\title{
Coronary microvascular resistance: methods for its quantification in humans
}

\author{
Paul Knaapen · Paolo G. Camici $\cdot$ Koen M. Marques $\cdot$ Robin Nijveldt $\cdot$ \\ Jeroen J. Bax · Nico Westerhof · Marco J. W. Götte · Michael Jerosch-Herold • \\ Heinrich R. Schelbert · Adriaan A. Lammertsma · Albert C. van Rossum
}

Received: 19 November 2008/Revised: 11 May 2009/Accepted: 13 May 2009/Published online: 26 May 2009

(C) The Author(s) 2009. This article is published with open access at Springerlink.com

\begin{abstract}
Coronary microvascular dysfunction is a topic that has recently gained considerable interest in the medical community owing to the growing awareness that microvascular dysfunction occurs in a number of myocardial disease states and has important prognostic implications. With this growing awareness, comes the desire to accurately assess the functional capacity of the coronary microcirculation for diagnostic purposes as well as to
\end{abstract}

P. Knaapen $(\bowtie) \cdot$ K. M. Marques $\cdot$ R. Nijveldt $\cdot$

M. J. W. Götte - A. C. van Rossum

Department of Cardiology, VU University Medical Center,

De Boelelaan 1117, 1081 HV Amsterdam, The Netherlands

e-mail: p.knaapen@vumc.nl

P. G. Camici

MRC Clinical Science Center, Imperial College,

National Heart and Lung Institute, Hammersmith Campus,

London, UK

J. J. Bax

Department of Cardiology, Leiden University Medical Center, Leiden, The Netherlands

N. Westerhof

Laboratory of Physiology, Department of Pulmonology,

VU University Medical Center, Amsterdam, The Netherlands

M. Jerosch-Herold

Department of Radiology, Brigham and Women's Hospital,

Harvard Medical School, Boston, MA, USA

H. R. Schelbert

Department of Molecular and Medical Pharmacology,

David Geffen School of Medicine at UCLA,

University of California at Los Angeles, Los Angeles, CA, USA

A. A. Lammertsma

Department of Nuclear Medicine and PET Research,

VU University Medical Center, Amsterdam, The Netherlands monitor the effects of therapeutic interventions that are targeted at reversing the extent of coronary microvascular dysfunction. Measurements of coronary microvascular resistance play a pivotal role in achieving that goal and several invasive and noninvasive methods have been developed for its quantification. This review is intended to provide an update pertaining to the methodology of these different imaging techniques, including the discussion of their strengths and weaknesses.

Keywords Coronary microvascular resistance . Imaging $\cdot$ Perfusion

\section{Introduction}

The heart relies on myocardial perfusion for supply of oxygen and substrates necessary to maintain contractile function [11]. Under physiological conditions, perfusion is tightly matched to metabolic demand. This is achieved by modulating coronary vascular resistance through adjustment of vascular tone. This process is under metabolic, endothelial, myogenic, and neurohumoral control $[5,16$, 70]. In the presence of a pathological increase in vascular resistance, as that resulting from a stenosis of an epicardial artery, regulatory mechanisms may become progressively exhausted and blood supply may fall short relative to demand, promptly resulting in myocardial ischemia as myocardial oxygen extraction can only slightly increase in ischemic conditions. Traditionally, identification and treatment of augmented coronary resistance have focused on obstructive atherosclerosis of the epicardial arteries. However, over the past two decades it has become increasingly apparent that augmented vascular resistance may also reside in the coronary microcirculation in a 
number of clinical conditions [13, 39]. Moreover, the severity of coronary microvascular dysfunction has been shown to be a powerful predictor of an adverse clinical outcome [14, 78]. Consequently, accurate assessment of coronary microvascular resistance (CMVR) has gained considerable interest, including the identification of potentially modifiable determinants for therapeutic purposes.

Conventional flow reserve measurements, using invasive and noninvasive techniques, are frequently used to test the integrity of the microcirculation [95, 102]. As will be discussed, however, their dependence on hemodynamic conditions and cardiac function limits the conclusions that can be derived from these measurements. Recent advances in different imaging modalities offer the possibility to quantify myocardial perfusion and resistance in absolute terms and to correct for some of these confounders. This review is intended to provide an update on the quantitative assessment of CMVR, together with its strengths and limitations, with particular emphasis on the noninvasive approach.

\section{Coronary microvascular resistance}

Resistance equals pressure-gradient divided by flow. In the case of the heart, the mean aortic to coronary back pressure (vide infra) gradient divided by total sinus coronary blood flow yields total coronary resistance $\left(\mathrm{mmHg} \mathrm{mL} \mathrm{min}^{-1}\right)$, although it must be acknowledged that Thebesian flow draining directly to the ventricular and atrial cavities is unaccounted for [93]. The coronary system can roughly be divided into three separate resistance components, being the conduit epicardial arteries, the arterioles, and the capillary-venous compartment $[70,106]$. Under normal physiological conditions, resistance is principally determined by vasomotor regulation of the arterioles with a diameter of less than $400 \mu \mathrm{m}$ and flow is kept constant over a wide range of perfusion pressures, i.e., flow is autoregulated [16, 70, 76, 118]. The control mechanisms involved in autoregulation are numerous and have been reviewed elsewhere $[5,44,106]$. The plateau level of resting flow, as depicted in Fig. 1, is matched to oxidative metabolism, which in turn is predominantly determined by heart rate, wall stress, and contractile state [11]. Therefore, knowledge of coronary resistance under baseline conditions mainly reflects basal metabolism, although it is also influenced by vascular rarefaction in LV hypertrophy and conditions where arterial oxygen content is reduced such as anemia [12]. Only when faced with a subtotal stenosis of an epicardial artery will coronary resistance be significantly augmented and cannot be compensated for by autoregulation [108]. In the absence of collaterals, this condition

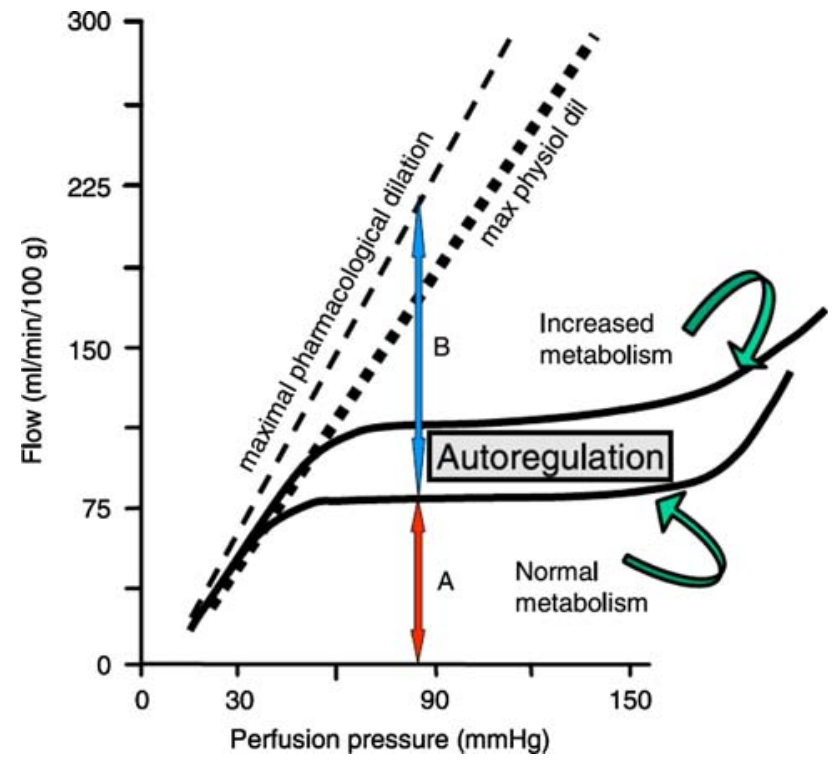

Fig. 1 Autoregulation maintains flow during constant metabolism. Over the autoregulation range, i.e., the plateau of the autoregulation curve, flow is rather constant for a range of perfusion pressures. The level of the plateau is related to the metabolic state of the heart. The dashed line indicates maximal pharmacological vasodilation. The dotted line shows the maximal physiological dilation, which is slightly smaller than can be reached pharmacologically. The flow reserve is given by the ratio $(B+A) / A$. Flow reserve is dependent on the basal level of myocardial metabolism, irrespective of minimum hyperemic coronary resistance. It should be noted that these relations are derived from isolated heart preparation studies where perfusion pressure and workload can be controlled independently. Human physiology in vivo usually operates within a smaller range of pressure and flow, and the close correlation between systolic pressure and oxidative metabolism results in a much narrower plateau phase of relative constant flow. Reprinted with permission from Westerhof et al. [118]

results in hampered resting perfusion and ultimately invariably results in tissue necrosis, although mild reductions in resting flow may be tolerated for an unknown period of time [42, 119]. However, when autoregulation is exhausted, minimal resistance can be calculated. Thus, when one wants to evaluate the performance of the microvascular bed and quantify minimal CMVR, the following conditions should ideally be met: (1) exclude the presence of obstructive epicardial coronary artery disease or determine driving pressure distal to an epicardial stenosis, (2) quantify flow, (3) induce maximal vasodilatation while recording pressure and flow, and (4) correct for coronary back pressure. The latter parameter is, however, difficult to measure as it is composed of multiple hemodynamic factors such as central venous pressure, coronary venous pressure, extravascular compressive forces such as $\mathrm{LV}$ end-diastolic pressure, and is further complicated by zero flow pressure [3]. As discussed below in more detail, in clinical studies many investigators, therefore, assume it to be zero or to be equivalent to right atrial pressure. In 
conditions of high arterial perfusion pressure and low coronary back pressure, this assumption is of little significance. In contrast, when arterial perfusion pressure is low, e.g., distal to a significant epicardial coronary stenosis, and/ or coronary back pressure is high, this approach will result in potential erroneous quantification of CMVR [118].

It is also important to realize that minimal CMVR is governed by intravascular as well as extravascular forces [118]. The former represents the conductance of the coronary microvessels themselves, whereas the latter is affected by mechanical cross-talk between contracting myocardium and the coronary vasculature such as diastolic perfusion time, cardiac contraction, and LV diastolic wall stress [44, 118]. In other words, CMVR is determined not only by intrinsic characteristics of the microvessels, but also by cardiac function where increased intra- and extramyocardial forces of the beating heart can impede coronary flow.

\section{Coronary flow reserve}

Coronary flow reserve (CFR) is defined as the ratio of peak hyperemic to resting flow. At a first glance, a reduction in flow reserve seems indicative of an increase in minimal coronary resistance and, in the absence of obstructive epicardial coronary artery disease, is therefore frequently used as an index of microvascular dysfunction. Of interest, absolute quantification of perfusion is not mandatory for the calculation of CFR, as the ratio of semi-quantitative perfusion indices will also yield a flow ratio. Unfortunately, as can be appreciated from Fig. 1, for a given level of hyperemic flow, CFR strongly depends on changes in the plateau level of resting perfusion. Although normalization of resting flow for heart rate and blood pressure may standardize this parameter, its correction remains incomplete. The magnitude of hyperemic perfusion, in turn, is likewise affected by hemodynamic conditions such as driving pressure and heart rate. The dependence of flow reserve on hemodynamic conditions and cardiac function therefore limits its use as a reliable and reproducible marker of microvascular disease [88]. Minimal CMVR should therefore be considered a more quantitative measure of microvascular function and the preferred parameter to study microvascular disease.

\section{Invasive quantification of minimal CMVR}

Invasive catheter-based quantification of minimal CMVR can be performed at a global or regional level [56, 101]. For the global approach, the coronary sinus is selectively catheterized and flow is measured with the use of the thermodilution technique. This technique is based on the general indicator dilution theory [74], which has been validated in the human heart to quantify global myocardial blood flow [28]. After a bolus or continuous injection of saline of a known volume and temperature, the temperature curve registration, a few centimeters distal to the injection site, allows for the computation of absolute volumetric flow, expressed in $\mathrm{mL} \mathrm{min}^{-1}$. The regional approach requires catheterization of one of the major coronary arteries and flow can again be measured using the thermodilution technique [82]. Alternatively, flow velocity can be measured with the use of a Doppler guide wire advanced into the epicardial coronary artery [25]. Current state-ofthe-art single guide wires allow for the assessment of flow velocity and pressure simultaneously to determine CMVR $[2,82,98]$. As the Doppler signal yields flow velocity only, conversion to volumetric flow requires exact knowledge of the vessel lumen dimensions, i.e., the cross-sectional area, that can be obtained through either quantitative coronary angiography (QCA) or intravascular ultrasound (IVUS) $[32,96,114]$.

The measurements need to be performed during maximal pharmacological vasodilatation induced either regionally (i.e., intracoronary adenosine bolus dose 30-60 or 20-30 $\mu \mathrm{g}$ for left or right coronary artery, respectively, or papaverine 15 or $10 \mathrm{mg}$, respectively) or systemically (i.e., intravenous adenosine dose $140 \mu \mathrm{g} \mathrm{kg}^{-1} \mathrm{~min}^{-1}$ or dipyridamole dose $0.56 \mathrm{mg} \mathrm{kg}^{-1}$ ) to achieve minimal coronary resistance [56]. It should be noted that the level of vasodilatation induced with dipyridamole is slightly less than with adenosine, leading to small differences in minimal hyperemic CMVR [15]. Furthermore, vasodilatation induced with these pharmacological vasodilating agents (i.e., causing uncoupling between perfusion and metabolic demand) appears to somewhat exceed the physiologically mediated response (i.e., retained coupling between perfusion and metabolic demand) (Fig. 1) [50, 118]. Of interest, alpha-adrenergic-mediated coronary vasoconstriction may even precipitate an increase in CMVR [39, 40]. Under physiologic circumstances, there is very little alphaadrenergic coronary vasomotor tone at rest, and hyperemic blood flow is only somewhat blunted [69]. Under conditions such as endothelial dysfunction and atherosclerosis, however, alpha-adrenergic-mediated coronary vasoconstriction is enhanced $[6,53,120]$. In patients with established coronary artery disease, alpha-adrenoceptor activation induces augmented coronary vasoconstriction, which is powerful enough to induce myocardial ischemia [6, 89]. Both, alpha $1^{-}$and alpha ${ }_{2}$-adrenoceptors mediate such coronary vasoconstriction, with alpha ${ }_{2}$-adrenoceptors more predominant in the microcirculation [17, 41]. Notably, reflex alpha-adrenergic coronary vasoconstriction is also elicited during coronary interventions [34, 49], and 
this contributes to postinterventional contractile dysfunction $[36,37]$. The distribution pattern of increased CMVR under these ischemic conditions appears to be very heterogeneous [90]. Infusion of adenosine subsequently lowers minimal CMVR and alleviates signs and symptoms of ischemia $[89,90]$. Antagonizing the $\alpha$-adrenergetic receptors may further enhance hyperemic perfusion on top of the aforementioned vasodilating agents, particularly during pathological conditions such as ischemia, in part mediated by the prolongation of diastolic perfusion time [35, 39, 64]. Finally, although beyond the scope of this review, endothelium coronary microvascular function can be tested separately through endothelium-dependent-mediated vasodilating agents, such as intracoronary acetylcholine.

Using pressure-flow relations measured within a coronary artery, the diastolic coronary pressure-flow (P-F) relationship can also be used to assess microvascular resistance. This relationship is essentially linear at perfusion pressures $>40 \mathrm{mmHg}$ but is appreciably curved at lower pressures. The curvilinearity is explained by gradually declining diameters of microvascular vessels at low pressures. Diastolic coronary flow stops at a coronary pressure far above right atrial pressures. The zero flow pressure is considered as a back pressure that affects coronary driving pressure. The mechanism and interpretation of the zero flow pressure are still a matter of debate [59, 100]. Two theories have been proposed to explain this phenomenon: a vascular waterfall theory and an intramyocardial pump model theory. In the former, vascular collapse is assumed to take place at very low pressure. The latter model is explained by the fact that the intramyocardial blood volume and blood pressure change more slowly than arterial pressure due to large time constants for charging and discharging the intramyocardial compliance. So, intramyocardial blood is still streaming even when epicardial coronary blood flow has stopped. The curvilinearity of the $\mathrm{P}-\mathrm{F}$ relation implies that microvascular resistance does not remain constant during one cardiac cycle. Furthermore, to determine the zero flow pressure, a very long diastole is needed; in a normal clinical situation, the next cardiac cycle is starting long before coronary flow of the previous cardiac cycle has become zero. For these reasons, the P-F relation and zero flow pressure are very hard to use in clinical practice and therefore will not be further discussed in this review. In clinical studies, right atrial pressure can be advocated as an estimate of coronary back pressure to calculate CMVR.

\section{Strengths and limitations}

The major advantage of the catheter-based approach is the fact that coronary angiography can be performed to exclude obstructive atherosclerosis of the epicardial arteries during the same session as the CMVR measurements. Moreover, in the presence of an epicardial obstructive stenosis, regional CMVR can be determined by assessing pressure and flow distal to the lesion [72]. In these instances, distal pressure measurements can distinguish coronary epicardial from microvascular resistance. The contribution of the epicardial stenosis to total coronary resistance can additionally be evaluated by determining the pressure drop over the epicardial stenosis (fractional flow resserve, FFR) [71, 72]. Finally, acute effects of (coronary) interventions on CMVR can be monitored, particularly in target vessel coronary arteries $[89,112]$. There are, however, several limitations that deserve attention.

First, the thermodilution technique has drawbacks. Stable positioning of the catheter, especially in the coronary sinus, can be difficult $[28,73,117]$. Furthermore, absolute quantification of flow requires accurate registration of the temperature and volume of the injected indicator (saline) at the injection and the downstream temperature recording at the distal site. These types of measurements have proven to be problematic and display relatively high variability, e.g., due to incomplete mixing of saline and blood $[73,117]$. Mixing problems appear to be smaller for bolus injections than for continuous infusion of saline [2].

Given these technical limitations, Pijls and colleagues have developed and validated a simplified thermodilution model where an index rather than quantitative flow is obtained by registration of the mean transit time of the indicator, disregarding absolute temperature changes [19, 82]. Thereafter, a semi-quantitative, unit-less index of microcirculatory resistance can be calculated [26]. Although experience is limited, mean transit time could also be determined using X-ray densitometry [38].

Second, although blood flow velocity measurements from Doppler signals are robust, determination of the cross-sectional area of the vessel for subsequent conversion to absolute flow remains problematic [25]. QCA requires angiography from at least two, but preferably more, angles and is accompanied by time consuming post-processing [32, 96]. IVUS yields qualitatively excellent images and accurate cross-sectional area estimates, but is expensive and less widely available [114]. To circumvent the additional crosssectional area imaging, a similar index of resistance as mentioned above has been introduced by Meuwissen and coworkers [75]. The so-called velocity-based index of CMVR equals the central arterial pressure divided by flow velocity obtained with Doppler and is expressed in $\mathrm{mmHg} \mathrm{cm} \mathrm{c}^{-1} \mathrm{~s}^{-1}$.

Third, in the presence of an obstructive coronary lesion, collateral flow becomes increasingly important with increasing stenosis severity. The above-described techniques do not account for collateral flow and therefore overestimate actual microvascular resistance [1]. Although 
this effect can be determined by measuring pressure and flow distal to the lesion during wedging of the coronary artery, these measurements are cumbersome and introduce additional room for error that hinder the interpretation of the obtained data. Apart from these technical limitations, the invasive nature of the procedure, exposure to ionizing radiation, and use of nephrotoxic contrast agents are general limitations that must also be taken into account.

\section{Noninvasive quantification of minimal CMVR}

Noninvasive measurement of CMVR can be obtained with positron emission tomography (PET), cardiovascular magnetic resonance imaging (CMR), or echocardiography. As will be discussed below, each of these imaging modalities allows for the absolute quantification of perfusion with the aid of radiolabeled or contrast agents, and also enable to detect regional variability [29, 33, 90, 105]. Characteristics of each modality are given in Table 1. During these noninvasive perfusion studies, the coronary driving pressure can simply be obtained by measuring mean arterial blood pressure with the use of a sphygmomanometer. As already mentioned, systemic vasodilatation is usually achieved by the infusion of adenosine or dipyridamole.

Depending on the spatial resolution of the imaging modality, perfusion and resistance can even be distinguished between the subendocardial and subepicardial layers. The latter is of pathophysiological importance as ischemia principally occurs in the subendocardium [27, 43]. Furthermore, diastolic perfusion time has proved to be an important determinant of subendocardial ischemia and can simultaneously be assessed using echocardiography and CMR [27, 109].

Table 1 Characteristics of different imaging modalities regarding absolute quantification of myocardial perfusion

\begin{tabular}{llll}
\hline & PET & CMR & MCE \\
\hline Radiation & Yes & No & No \\
Costs & High & Moderate & Low \\
Availability & Limited & Limited & Widely \\
Safety & Good & Good & Moderate \\
Reproducibility & High & NA & NA \\
Validation kinetic model & Excellent & Good & Fair \\
LV coverage & Complete & Incomplete & Incomplete \\
Post-processing & Parametric & Manual & Manual \\
Spatial resolution & Moderate & High & High \\
LV function imaging & Moderate & Excellent & Good \\
\hline
\end{tabular}

$P E T$ positron emission tomography, $C M R$ cardiovascular magnetic resonance imaging, $M C E$ myocardial contrast echocardiography, $L V$ left ventricular, $N A$ not available
The major disadvantage that characterizes these noninvasive approaches pertains to the inability of these imaging modalities to exclude the proximal pressure drop in obstructive epicardial coronary artery disease to distinguish microvascular from epicardial stenosis resistance. Although it is important to bear in mind that coronary microvascular dysfunction is often a global process, reference areas with relatively preserved hyperemic perfusion can be still used to quantify CMVR. The adjacent more severely blunted perfusion areas are then assumed to be caused by epicardial lesions.

\section{General considerations of perfusion quantification}

The general principle of quantitative perfusion imaging is based on the registration of the exchange of tracer concentration between arterial blood and myocardial tissue over time, where the ideal perfusion tracer accumulates in or clears from myocardium proportionally to $\mathrm{MBF}$ and is not affected by the magnitude of flow and pathophysiological conditions [54]. For all tracers, the activity concentration in myocardium (i.e., the tissue response to the injected tracer) is dependent on the product of MBF, the tracer extraction fraction, and the arterial input function. In other words, MBF can be calculated when myocardial and arterial concentrations are measured over time and tracer extraction fraction is known. The latter value equals unity for completely freely diffusible tracers, although for most tracers, the first pass extraction is less than 1 and declines nonlinearly relation with increasing MBF, complicating quantification of flow.

\section{Positron emission tomography}

For PET perfusion imaging, two tracers in particular have been well validated and are routinely used for quantification of myocardial blood flow: oxygen- 15 labeled water $\left(\mathrm{H}_{2}^{15} \mathrm{O}\right)$ and nitrogen-13 labeled ammonia $\left({ }^{13} \mathrm{NH}_{3}\right)[7,94]$. The scanning procedure for both tracers is comparable where after an intravenous bolus injection of the perfusion tracer simultaneously a dynamic emission is performed. Figure 2 shows an example of such a dynamic cardiac ${ }^{13} \mathrm{NH}_{3}$ PET acquisition and its corresponding time activity curves for regions of interest derived from the LV cavity and the myocardium.

Based on the known biological behavior of the two tracers, kinetic compartment models have been developed to quantify MBF in absolute terms $\left(\mathrm{mL} \mathrm{min}^{-1} \mathrm{~g}^{-1}\right.$ ). There are, however, some important differences in characteristics between $\mathrm{H}_{2}^{15} \mathrm{O}$ and ${ }^{13} \mathrm{NH}_{3}$ MBF measurements that are listed in Table 2. Two particular technical aspects are worth discussing in more detail. 


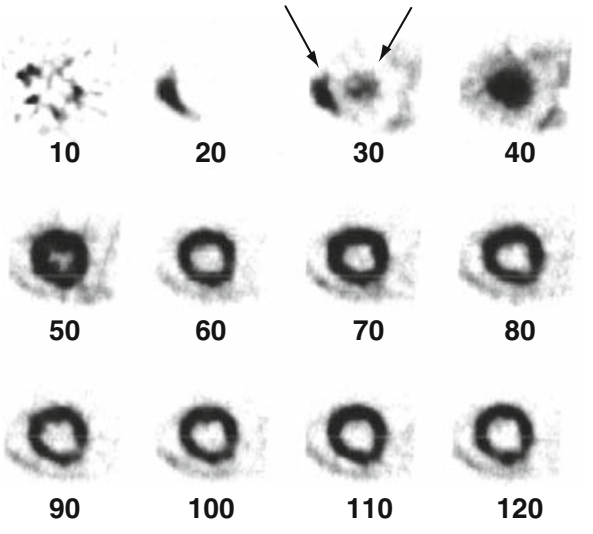

Fig. 2 Serially acquired short axis PET images following the intravenous injection of ${ }^{13} \mathrm{~N}$-ammonia. Ten-second images are shown. Notice in the second image the activity in the right ventricular cavity, and visualization of the left ventricular blood pool on the next image, and thereafter accumulation of the tracer in the myocardium and clearance from blood. The corresponding time-activity curves for

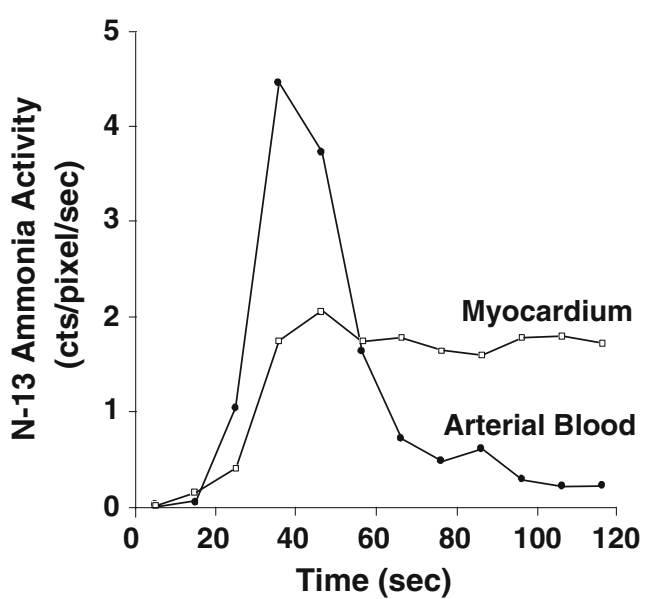

arterial blood and myocardial tissue are also displayed. The dynamic flux of tracer from arterial blood to tissue is modeled to convey absolute units of perfusion. Reprinted with permission from 'PET: molecular imaging and its biological applications', edited by Michael E. Phelps (2004) Springer-Verlag, New York, Inc

Table 2 Characteristics of oxygen-15-labeled water $\left(\mathrm{H}_{2}^{15} \mathrm{O}\right)$ and nitrogen-13-labeled ammonia $\left({ }^{13} \mathrm{NH}_{3}\right)$ for PET perfusion imaging

\begin{tabular}{|c|c|c|c|}
\hline & $\mathrm{H}_{2}^{15} \mathrm{O}$ & ${ }^{13} \mathrm{NH}_{3}$ & Comment \\
\hline Half-life & $2 \min$ & $10 \mathrm{~min}$ & $\begin{array}{l}\text { Five half-lives are required for a repeated } \\
\text { measure }\end{array}$ \\
\hline Production & Cyclotron & Cyclotron & $\begin{array}{l}\text { An on-site cyclotron is necessary given the } \\
\text { short half-lifes of the tracers }\end{array}$ \\
\hline Kinetics & $\begin{array}{l}\text { Freely diffusible; } \\
\text { metabolically inert }\end{array}$ & $\begin{array}{l}\text { Metabolically trapped in } \\
\text { myocardium }\end{array}$ & $\begin{array}{l}\text { Greater activity gradient between arterial } \\
\text { blood and myocardium for }{ }^{13} \mathrm{NH}_{3} \text {, yielding } \\
\text { superior qualitative images }\end{array}$ \\
\hline First pass extraction & Complete & $\begin{array}{l}\text { Incomplete in a nonlinear fashion } \\
\text { with increasing MBF }\end{array}$ & $\begin{array}{l}\text { Corrections for incomplete extraction of } \\
{ }^{13} \mathrm{NH}_{3} \text { with increasing MBF required }\end{array}$ \\
\hline $\begin{array}{l}\text { Modeling quantification } \\
\text { parameter }\end{array}$ & Tracer wash-out & Tracer uptake & $\begin{array}{l}\text { Perfusable versus transmural estimates of } \\
\text { MBF; see text for details }\end{array}$ \\
\hline
\end{tabular}

First, $\mathrm{H}_{2}^{15} \mathrm{O}$ is a metabolically inert and freely diffusible molecule which has a virtual complete extraction into the myocardium, independent of flow rate and metabolic state. Therefore, regional differences in myocardial tissue response are solely dependent on perfusion, rendering this tracer ideal for quantification of flow. Conversely, the ${ }^{13} \mathrm{NH}_{3}$ extraction fraction decreases with increasing flow rates, leading to underestimation of perfusion with higher flow values unless of course they are corrected for by the tracer compartment model. In fact, these corrections have been thoroughly tested and perfusion values obtained with $\mathrm{H}_{2}^{15} \mathrm{O}$ and ${ }^{13} \mathrm{NH}_{3}$ yield comparable results and match with the gold standard of microsphere-determined perfusion $[9,79]$.

Second, the modeling procedures of the tracers differ in that perfusion is estimated from the wash-out phase of the radiolabeled tracer in $\mathrm{H}_{2}^{15} \mathrm{O}$ studies, whereas for ${ }^{13} \mathrm{NH}_{3}$ the myocardial uptake is used [47, 65]. These methodological differences do not affect perfusion measurements in normal myocardium [15, 79], but lead to different flow estimates in myocardium with scar tissue [9]. As perfusion in scar tissue is negligible, uptake of flow tracers will take place in viable or normal myocardium only [48]. Consequently, wash-out of $\mathrm{H}_{2}^{15} \mathrm{O}$ is related only to the water perfusable tissue fraction so that estimates of blood flow are limited to normal or viable myocardium. Estimates of perfusion from the wash-out phase with $\mathrm{H}_{2}^{15} \mathrm{O}$ will therefore reflect flow in viable perfusable tissue only. In contrast, estimating perfusion derived from tracer uptake using ${ }^{13} \mathrm{NH}_{3}$ will reflect the admixture of scar and viable tissue, i.e., transmural perfusion [60]. In practice, this means that, in the presence of scar tissue, perfusion measured with ${ }^{13} \mathrm{NH}_{3}$ will yield lower values compared with $\mathrm{H}_{2}^{15} \mathrm{O}$ in direct proportion to the magnitude of the present myocardial scar. This 
technical feature has been used to quantify coronary CMVR in residual viable myocardium after a myocardial infarction in humans using $\mathrm{H}_{2}^{15} \mathrm{O}$ PET [71, 72, 107].

\section{Strengths and limitations}

For the last two decades, PET has served as the gold standard for noninvasive absolute quantification of myocardial blood flow (MBF) and CMVR [54]. Both tracers have been shown to accurately quantify MBF in absolute units over a wide flow range and correlate well with values obtained after injection of radiolabeled microspheres, both at a regional and global level [9]. Furthermore, reproducibility was shown to be good [55, 77], and PET studies have provided normal references values for both resting and hyperemic MBF in healthy volunteers [15]. In addition, the relatively short half-life of the tracers, particularly $\mathrm{H}_{2}^{15} \mathrm{O}(120 \mathrm{~s})$, allows for serial measurements within a single session which enables the investigation of multiple interventions on perfusion and resistance [63]. Finally, in recent years, parametric imaging has significantly reduced the post-processing time by the omission of elaborate (manual) region of interest analysis, making this technique increasingly operator friendly [8, 31].

On the downside, perfusion PET suffers from its limited availability and high costs, which are mainly related to the necessity of an onsite cyclotron and expertise regarding the preparation and administration of the involved radiotracers. Also, PET imaging is accompanied by exposure to ionizing radiation, although the burden is relatively low using these short-lived tracers. Furthermore, the spatial resolution of PET is relatively low ( $\sim 5 \mathrm{~mm})$, resulting in partial volume and spillover effects. Sophisticated kinetic modeling parameters, however, can correct for these effects and advances in imaging instrumentation have even enabled the distinction between subendocardial and subepicardial perfusion, not only in the hypertrophied human heart but also in the normal sized myocardial wall $[61,85,86]$. Finally, although PET is the method of choice for noninvasive assessment of perfusion and metabolism, it does not provide suitable anatomical information compared with CMR and echocardiography. However, state-of-the-art hybrid imaging systems combining PET and CT offer anatomical, functional, and metabolic information in a single scan session [20, 62, 91, 92, 97].

\section{Cardiovascular magnetic resonance imaging}

Although initial attempts for (semi)quantitative assessment of MBF using CMR focused on velocity-encoded phase contrast imaging of either the proximal course of the coronary arteries or the coronary sinus [46, 110], recent myocardial CMR perfusion imaging approaches are mainly based on the changes in myocardial signal intensities during first pass of paramagnetic extracellular contrast agents, i.e., gadolinium chelates [51]. After an intravenous bolus injection of the contrast agent, an electrocardiogram-gated acquisition of approximately 30$60 \mathrm{~s}$ is started and myocardial and arterial signal intensities are recorded over time. The patient is normally asked to suspend breathing for $10-15 \mathrm{~s}$ after the bolus injection so that the initial myocardial contrast-enhancement can be observed without interference from breathing motion, although image quality is generally not affected by the breathing motion, but causes slice misregistration. Figure 3 displays such an imaging sequence. During the first pass of the contrast agent, a fraction of it rapidly diffuses through the capillary walls into the interstitium, where it reduces the $\mathrm{T} 1$ relaxation time and increases the signal intensity of the protons surrounding the contrast molecules. The myocardial signal intensity response to the arterial input, however, depends not only on the perfusion, but also on the tissue blood volume, the size of the extravascular compartment, and the degree of capillary permeability, which complicates quantitative analysis that must account for all these unknown variables [103, 104]. Therefore, for the purpose of only determining tissue blood flow, a model-independent approach based on the central volume principle of Zierler [121] was developed that focuses on the initial amplitude of the myocardial tissue response, which is, in theory, related to flow only. The area under the impulse response curve represents the (dynamic) volume of distribution during the first pass, and can provide a measure of vascular volume if an intravascular tracer is used. For extracellular tracers, such as gadolinium diethylenetriaminepenta-acetic acid, the impulse response is characterized by an initial rapid decay related to the vascular phase of contrast transit, and a prolonged tail that corresponds to the delayed wash-out of tracer that has passed from the capillaries into the interstitial space. The application of the model-independent analysis based on the central volume principle requires numerical deconvolution of the measured signal enhancement in tissue with an arterial input function derived from the measured signal enhancement in blood (e.g., in the ascending aorta or the left ventricular cavity). This model for absolute quantification of flow has subsequently been validated in animal experiments by comparing the blood flow measurements with radio-labeled microspheres [52], and thereafter been used in more large scaled clinical studies for the assessment of microvascular function [81, 87]. 


\section{Strengths and limitations}

Myocardial perfusion imaging using CMR has the advantage of high spatial resolution, no use of ionizing radiation, the use of readily available contrast agents, and no attenuation problems related to, e.g., overlying breast shadow. Furthermore, next to the information pertaining to perfusion, accurate assessment of regional myocardial wall motion and, using late-contrast enhanced images (approximately $10-15 \mathrm{~min}$ after injection), tissue morphology can be obtained in the same setting [10, 57, 58]. Moreover, advances in CMR imaging have now enabled accurate delineation of subendocardial and subepicardial perfusion [83, 84]. In combination with CMR-estimated diastolic perfusion time, not only regional resistance but also some of its determinants can be evaluated. There are, however, some important technical limitations that hamper the routine quantification of perfusion with CMR.

First and foremost importance, to achieve an adequate signal-to-noise ratio of the myocardial tissue enhancement as displayed in Fig. 3, relatively large doses of gadolinium are administered (from 0.05 up to more than $0.1 \mathrm{mmol} \mathrm{kg}^{-1}$ ). At these concentrations, however, the linear relationship between the measured signal intensity in the LV cavity and the actual contrast concentrations levels off. Therefore, for quantification purposes where the arterial input concentrations of contrast must reliably be defined, one should use much lower doses of gadolinium, i.e., in the order of $0.005-0.03 \mathrm{mmol} \mathrm{kg}{ }^{-1}$, to retain a linear relation between contrast concentration and the obtained signal. Unfortunately, these lower doses result in decreased contrast to noise ratios and loss of the possibility for visual analysis of the myocardial tissue response. To circumvent this problem, Christian et al. [18] have recently introduced and validated the so-called dual-bolus approach. Low and high concentration bolus injections of contrast are administered serially within a few-second interval, where the first is used for registration of the arterial input function and the second for tissue response. In this manner, high signal-to-noise tissue images are generated, additionally allowing qualitative visual interpretation, and fully quantitative computation can be performed using the input
Fig. 3 CMR short axis images (a-d) of the first pass of gadolinium contrast and activity curves of contrast (expressed in arbitrary units) plotted against time for the arterial left ventricular blood pool and two myocardial regions. A perfusion defect can be observed both visually on the images and from the activity registration in the anteroseptal area, where the peak intensity and slope of the curve are reduced. Note that tracer uptake in tissue occurs just seconds after the peak intensity of the input curve and remains fairly stable in the minute thereafter, as the contrast agent resides in the extracellular matrix after diffusion from the capillaries. Also note the recirculation of contrast after $25 \mathrm{~s}$ that induces a second peak in arterial blood.

Because the physiological behavior of the tracer is dependent on a variety of physiological parameters that cannot be modeled, only peak intensity levels of arterial blood and tissue are used to determine perfusion in absolute terms

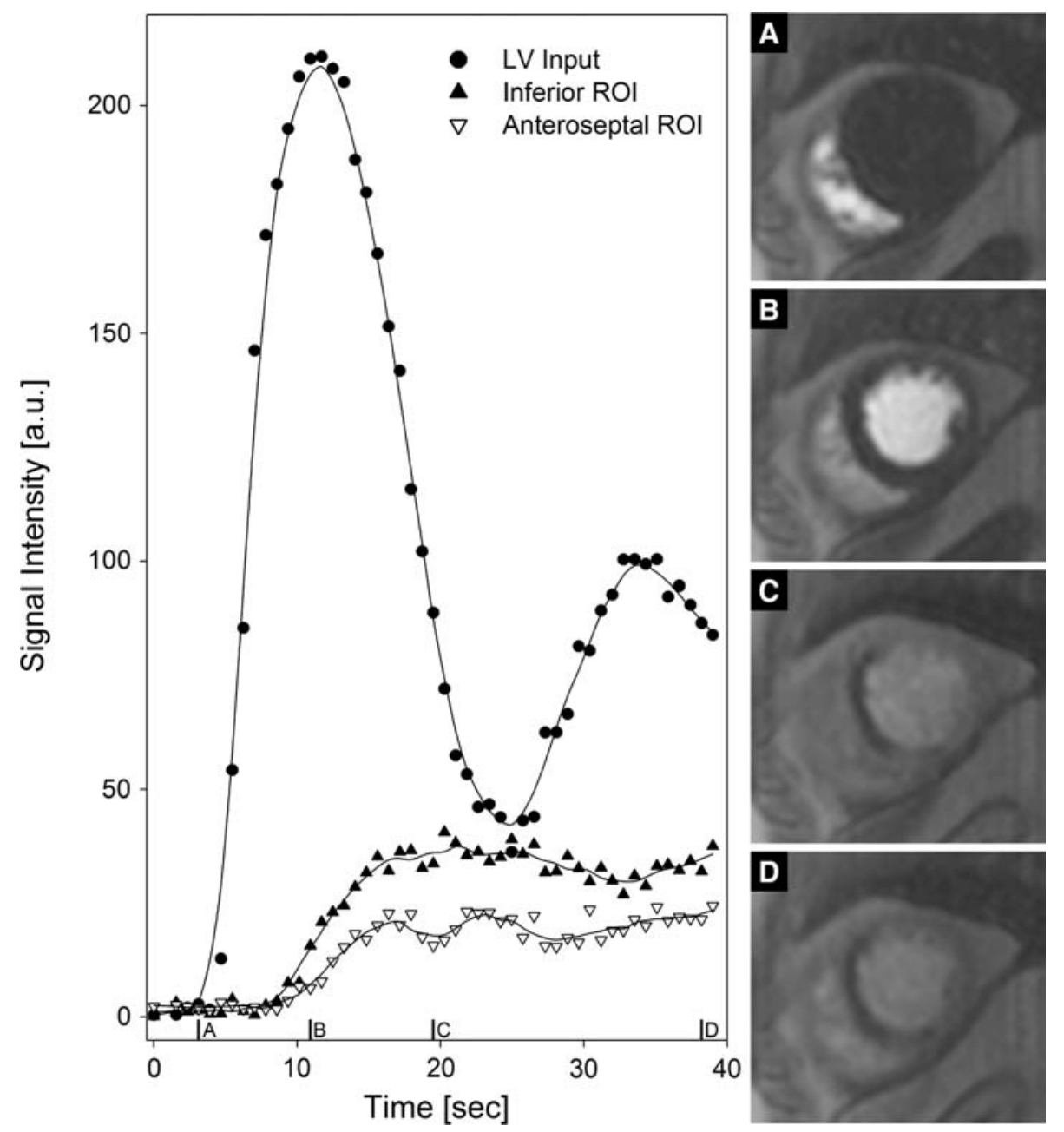


curve. In addition, the signal enhancement in tissue, despite being much lower than in the blood pool, may still be compromised by some saturation effects from the signal contributed by the vascular volume fraction in tissue. Therefore, one of the original proponents of the dual-bolus approach recently proposed a method for nonlinear myocardial signal intensity correction, but still assuming that myocardial tissue is a homogeneous space [45]. In addition to the dependence of the myocardial signal on the underlying structure of the tissue and the distribution of the contrast agent, one should also note that the $1 \mathrm{H}$ signal is not only affected by close contact with the contrast agent, but also by the exchange of water between different spaces in tissue, including spaces not directly accessible to the contrast agent [23, 24, 67].

Second, post-processing requires manual definition of myocardial regions of interest or segmentation along the endo- and epicardial borders, which is quite time consuming. Although efforts are being made to map perfusion on a pixel-by-pixel basis, these new analysis techniques are not yet routinely applicable [30]. Furthermore, the process of manual region delineation is complicated by patient motion during the breath-hold acquisition. In particular, the stress study is prone to motion artifacts that require frame by frame adjustment of the regions of interest.

Finally, recent attention has focused on the toxicity of gadolinium-based contrast agents, particularly in patients with chronic renal failure where its use is associated with nephrogenic systemic fibrosis [66]. In fact, these sideeffects have restricted its use to patients with a glomerular filtration rate of at least $30 \mathrm{~mL} \mathrm{~min} \min ^{-1}$ [115]. Also, some general restrictions prohibit perfusion imaging with $\mathrm{CMR}$, such as claustrophobia, myocardial arrhythmias, and implanted devices.

\section{Echocardiography}

Myocardial contrast echocardiography (MCE) for quantification of perfusion has become feasible with the recent development of an encapsulated microbubble contrast agent that remains confined to the intravascular space and behaves similarly as red blood cells in terms of rheology [68]. The microbubbles are continuously administered intravenously in order to reach a steady state with concentrations in arterial blood and myocardial tissue relatively constant. Subsequently, a high-power ultrasound pulse applied within the acoustic beam destroys the bubbles and the void is replenished within few seconds (Fig. 4a). The time-video intensity registration can be fitted to an exponential equation, i.e., $y=A\left(1-\mathrm{e}^{-\beta} t\right)$, where $A$ represents the (mainly capillary) myocardial blood volume and $\beta$ the rate constant that indicates the flow velocity of blood (Fig. 4b) [116]. The product of the two, therefore, provides an estimate on myocardial blood flow, which correlates with perfusion in canine experiments [116].

True quantification, however, is hindered by the fact that estimated myocardial blood volume is subjected to attenuation artifacts, such as the microbubbles present in the left ventricular cavity, and heterogeneity of the acoustic beam. Vogel et al. have recently circumvented this issue by standardizing the myocardial blood volume signal to the adjacent left ventricular blood pool signal (Fig. 4c). As
Fig. 4 a Example of intravenous myocardial contrast echocardiography, 3-chamber view during hyperemia: precontrast image $(a)$, high mechanical ultrasound pulse $(b)$, and subsequent replenishment of contrast $(c-h)$. b Example of mono-exponential time-video intensity curve. The slope of the initial phase of the curve represents the microbubble flow velocity, whereas the plateau phase indicates blood volume. c Region-of-interest placement for myocardial regions with adjacent left ventricular blood pool in a four-chamber view of a healthy volunteer. Reprinted with permission from Dijkmans et al. [21] (a, b), and from Vogel et al. [113] (c)
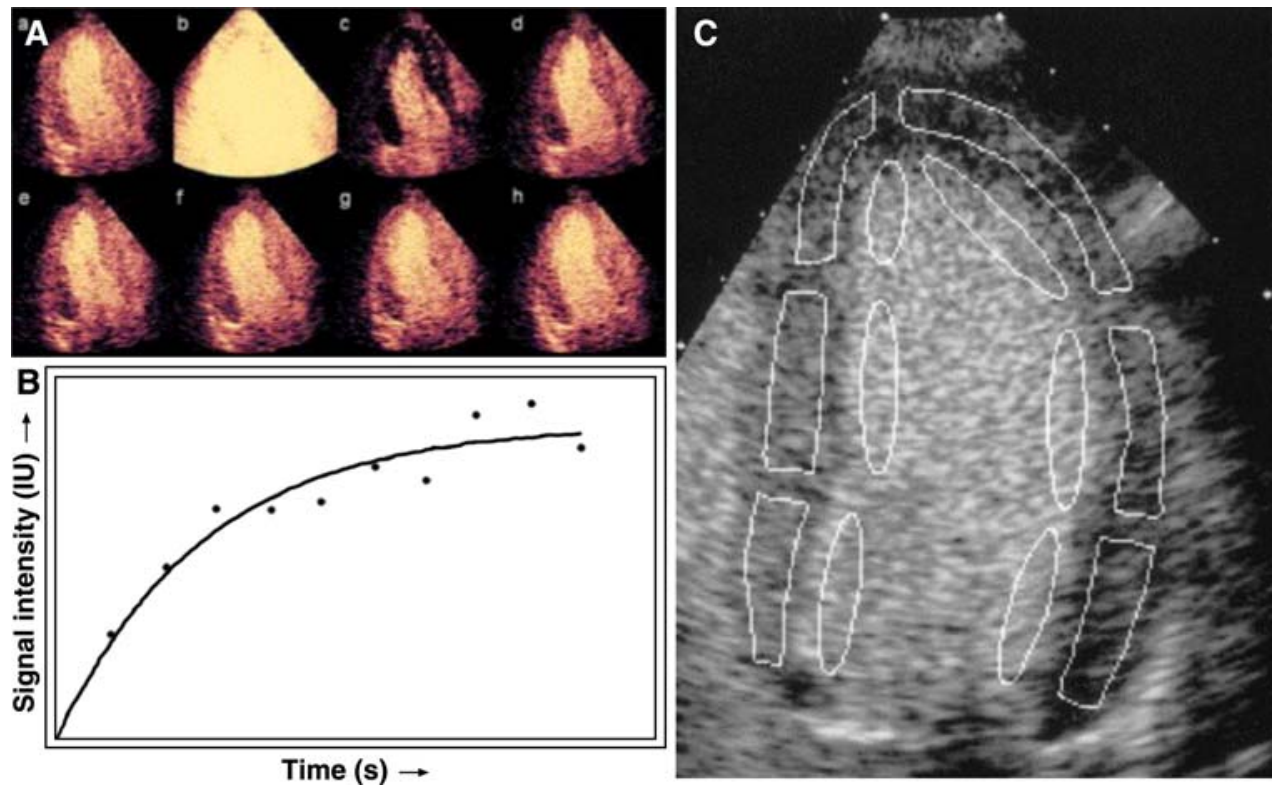
these signals are theoretically affected to a similar degree by these artifacts, they are filtered out using this approach [113]. Indeed, absolute quantification of perfusion with MCE correlated nicely with PET-obtained values in humans [113].

\section{Strengths and limitations}

Although MCE is relatively new in the field of perfusion imaging and requires operator demands that are not easily met, the potential for this technique is evident as echocardiography is widely available, and is characterized by high temporal and spatial resolution, and performs well in additional functional cardiac imaging. Despite these advantages, compared with PET and CMR, MCE must currently be considered the least accurate and attractive noninvasive perfusion imaging modality for two reasons.

First, there are some technical concerns. As commonly known, echocardiography suffers from a poor acoustic window in a not inconsequential percentage of patients. In general, about $10-15 \%$ of echo exams are of poor quality. Moreover, even when these patients have been excluded, a recent MCE perfusion study has shown that an additional $20 \%$ of myocardial segments were not suitable for the analysis [21]. Furthermore, the number of validation studies with MCE that have implemented the above-described model is limited [21, 113]. Unfortunately, the initial promising results of Vogel et al. [113] could not be reproduced by Dijkmans and co-workers [21], as the latter study revealed significantly more scatter in the obtained perfusion data as compared with PET. One of the possible explanations for the inaccuracy of the measurements, next to distortions in image quality, could be that the model assumes linearity between contrast concentrations and measured video intensity. This assumption, however, is incorrect in the higher range of microbubble concentrations as observed in the left ventricular cavity [99, 116]. Another issue, and similar to $\mathrm{CMR}$, is the tedious post-processing procedure that requires manual definition of regions of interest, prohibiting its use on a larger scale.

Second, there is an ongoing debate with respect to safety of the microbubble contrast agent [22]. Adverse allergic reactions have been frequently reported. Although these side effects generally do not result in permanent damage, it has led to regulations restricting the use of some brands in severely cardiovascular compromised patients [22]. Use of these agents, therefore, requires the attention of a physician at all times. In addition, both dog [4] and human [111] experiments have shown that the destruction of microbubbles by the ultrasound beam can result in microvascular damage. Although relatively low mechanical pulses seem reasonably safe, they in turn may result in incomplete bubble destruction, which reduces the quality of the study [80].

\section{Summary and conclusions}

With the growing awareness that coronary microvascular dysfunction is an important pathophysiological component in many cardiac conditions, comes the necessity to accurately assess the functional status of the microcirculation [13]. In trying to achieve this goal, absolute quantification of perfusion and pressure to determine minimum microvascular resistance plays a central role [70, 118]. This review has discussed the pros and cons of the currently available invasive and noninvasive techniques regarding these measurements. It can be concluded that the invasive approach is the preferred method in patients with epicardial obstructive coronary atherosclerosis as microvascular resistance can be determined distal to the epicardial lesion. Also, invasive measurements are most suitable to investigate acute effects of interventions. The noninvasive measurements with PET, CMR, or MCE to assess the coronary microcirculation can be used in patients in whom obstructive coronary artery disease is unlikely or, preferably, excluded by angiography. The advantages of noninvasive over invasive methodology are obvious. In particular, monitoring interventions that potentially modulate coronary microvascular dysfunction, which require serial measurements over longer periods of time, should benefit from a noninvasive approach. PET was proven to be the unrivalled imaging modality for absolute quantification of perfusion. The introduction of hybrid systems that combine PET with CT could be of additional benefit, as $\mathrm{CT}$ angiography could also exclude epicardial coronary artery disease in these patients. Perfusion quantification with CMR has rapidly evolved and, in the hands of few experienced centers, now offers an approach that combines absolute perfusion measurements with detailed functional, anatomical, and morphological cardiac information. MCE is the most accessible technique, and could theoretically be used in most research imaging centers. Technical limitations together with relatively inaccurate perfusion measurements and some safety concerns, however, have to date restricted widespread application of MCE.

Acknowledgments Robin Nijveldt is supported by NHS grant no. 2003 B126.

Open Access This article is distributed under the terms of the Creative Commons Attribution Noncommercial License which permits any noncommercial use, distribution, and reproduction in any medium, provided the original author(s) and source are credited. 


\section{References}

1. Aarnoudse W, Fearon WF, Manoharan G, Geven M, van de Vosse F, Rutten M, De Bruyne B, Pijls NH (2004) Epicardial stenosis severity does not affect minimal microcirculatory resistance. Circulation 110:2137-2142

2. Aarnoudse W, Van't Veer M, Pijls NH, Ter Woorst J, Vercauteren S, Tonino P, Geven M, Rutten M, van Hagen E, de Bruyne B, van de Vosse F (2007) Direct volumetric blood flow measurement in coronary arteries by thermodilution. $\mathrm{J}$ Am Coll Cardiol 50:2294-2304

3. Aversano T, Klocke FJ, Mates RE, Canty JM Jr (1984) Preloadinduced alterations in capacitance-free diastolic pressure-flow relationship. Am J Physiol 246:H410-H417

4. Ay T, Havaux X, Van Camp G, Campanelli B, Gisellu G, Pasquet A, Denef JF, Melin JA, Vanoverschelde JL (2001) Destruction of contrast microbubbles by ultrasound: effects on myocardial function, coronary perfusion pressure, and microvascular integrity. Circulation 104:461-466

5. Bassenge E, Heusch G (1990) Endothelial and neuro-humoral control of coronary blood flow in health and disease. Rev Physiol Biochem Pharmacol 116:77-165

6. Baumgart D, Haude M, Gorge G, Liu F, Ge J, Grosse-Eggebrecht C, Erbel R, Heusch G (1999) Augmented alpha-adrenergic constriction of atherosclerotic human coronary arteries. Circulation 99:2090-2097

7. Bergmann SR, Herrero P, Markham J, Weinheimer CJ, Walsh MN (1989) Noninvasive quantitation of myocardial blood flow in human subjects with oxygen-15-labeled water and positron emission tomography. J Am Coll Cardiol 14:639-652

8. Boellaard R, Knaapen P, Rijbroek A, Luurtsema GJ, Lammertsma AA (2005) Evaluation of basis function and linear least squares methods for generating parametric blood flow images using 15O-water and Positron Emission Tomography. Mol Imaging Biol 7:273-285

9. Bol A, Melin JA, Vanoverschelde JL, Baudhuin T, Vogelaers D, De Pauw M, Michel C, Luxen A, Labar D, Cogneau M et al (1993) Direct comparison of [13N]ammonia and [15O]water estimates of perfusion with quantification of regional myocardial blood flow by microspheres. Circulation 87:512-525

10. Botnar RM, Nagel E (2008) Structural and functional imaging by MRI. Basic Res Cardiol 103:152-160

11. Braunwald E (1971) Control of myocardial oxygen consumption: physiologic and clinical considerations. Am J Cardiol 27:416-432

12. Camici P, Marraccini P, Marzilli M, Lorenzoni R, Buzzigoli G, Puntoni R, Boni C, Bellina CR, Klassen GA, L'Abbate A et al (1989) Coronary hemodynamics and myocardial metabolism during and after pacing stress in normal humans. Am J Physiol 257:E309-E317

13. Camici PG, Crea F (2007) Coronary microvascular dysfunction. N Engl J Med 356:830-840

14. Cecchi F, Olivotto I, Gistri R, Lorenzoni R, Chiriatti G, Camici PG (2003) Coronary microvascular dysfunction and prognosis in hypertrophic cardiomyopathy. $\mathrm{N}$ Engl $\mathrm{J}$ Med 349:1027-1035

15. Chareonthaitawee P, Kaufmann PA, Rimoldi O, Camici PG (2001) Heterogeneity of resting and hyperemic myocardial blood flow in healthy humans. Cardiovasc Res 50:151-161

16. Chilian WM (1997) Coronary microcirculation in health and disease. Summary of an NHLBI workshop. Circulation 95:522528

17. Chilian WM (1991) Functional distribution of alpha 1- and alpha 2-adrenergic receptors in the coronary microcirculation. Circulation 84:2108-2122
18. Christian TF, Rettmann DW, Aletras AH, Liao SL, Taylor JL, Balaban RS, Arai AE (2004) Absolute myocardial perfusion in canines measured by using dual-bolus first-pass MR imaging. Radiology 232:677-684

19. De Bruyne B, Pijls NH, Smith L, Wievegg M, Heyndrickx GR (2001) Coronary thermodilution to assess flow reserve: experimental validation. Circulation 104:2003-2006

20. Di Carli MF, Dorbala S, Meserve J, El Fakhri G, Sitek A, Moore SC (2007) Clinical myocardial perfusion PET/CT. J Nucl Med 48:783-793

21. Dijkmans PA, Knaapen P, Sieswerda GT, Aiazian E, Visser CA, Lammertsma AA, Visser FC, Kamp O (2006) Quantification of myocardial perfusion using intravenous myocardial contrast echocardiography in healthy volunteers: comparison with positron emission tomography. J Am Soc Echocardiogr 19:285-293

22. Dijkmans PA, Visser CA, Kamp O (2005) Adverse reactions to ultrasound contrast agents: is the risk worth the benefit? Eur J Echocardiogr 6:363-366

23. Donahue KM, Weisskoff RM, Burstein D (1997) Water diffusion and exchange as they influence contrast enhancement. J Magn Reson Imaging 7:102-110

24. Donahue KM, Weisskoff RM, Chesler DA, Kwong KK, Bogdanov AA Jr, Mandeville JB, Rosen BR (1996) Improving MR quantification of regional blood volume with intravascular T1 contrast agents: accuracy, precision, and water exchange. Magn Reson Med 36:858-867

25. Doucette JW, Corl PD, Payne HM, Flynn AE, Goto M, Nassi M, Segal J (1992) Validation of a Doppler guide wire for intravascular measurement of coronary artery flow velocity. Circulation 85:1899-1911

26. Fearon WF, Balsam LB, Farouque HM, Caffarelli AD, Robbins RC, Fitzgerald PJ, Yock PG, Yeung AC (2003) Novel index for invasively assessing the coronary microcirculation. Circulation 107:3129-3132

27. Fokkema DS, VanTeeffelen JW, Dekker S, Vergroesen I, Reitsma JB, Spaan JA (2005) Diastolic time fraction as a determinant of subendocardial perfusion. Am J Physiol Heart Circ Physiol 288:H2450-H2456

28. Ganz W, Tamura K, Marcus HS, Donoso R, Yoshida S, Swan HJ (1971) Measurement of coronary sinus blood flow by continuous thermodilution in man. Circulation 44:181-195

29. Gimelli A, Schneider-Eicke J, Neglia D, Sambuceti G, Giorgetti A, Bigalli G, Parodi G, Pedrinelli R, Parodi O (1998) Homogeneously reduced versus regionally impaired myocardial blood flow in hypertensive patients: two different patterns of myocardial perfusion associated with degree of hypertrophy. J Am Coll Cardiol 31:366-373

30. Goldstein TA, Jerosch-Herold M, Misselwitz B, Zhang H, Gropler RJ, Zheng J (2008) Fast mapping of myocardial blood flow with MR first-pass perfusion imaging. Magn Reson Med 59:1394-1400

31. Golish SR, Hove JD, Schelbert HR, Gambhir SS (2001) A fast nonlinear method for parametric imaging of myocardial perfusion by dynamic (13)N-ammonia PET. J Nucl Med 42:924-931

32. Gould KL (1988) Identifying and measuring severity of coronary artery stenosis. Quantitative coronary arteriography and positron emission tomography. Circulation 78:237-245

33. Graf K, Grafe M, Fleck E (2008) Cardiovascular diseases as target for imaging. Basic Res Cardiol 103:82-86

34. Gregorini L, Fajadet J, Robert G, Cassagneau B, Bernis M, Marco J (1994) Coronary vasoconstriction after percutaneous transluminal coronary angioplasty is attenuated by antiadrenergic agents. Circulation 90:895-907

35. Gregorini L, Marco J, Farah B, Bernies M, Palombo C, Kozakova M, Bossi IM, Cassagneau B, Fajadet J, Di Mario C, 
Albiero R, Cugno M, Grossi A, Heusch G (2002) Effects of selective alpha1- and alpha2-adrenergic blockade on coronary flow reserve after coronary stenting. Circulation 106:29012907

36. Gregorini L, Marco J, Kozakova M, Palombo C, Anguissola GB, Marco I, Bernies M, Cassagneau B, Distante A, Bossi IM, Fajadet J, Heusch G (1999) Alpha-adrenergic blockade improves recovery of myocardial perfusion and function after coronary stenting in patients with acute myocardial infarction. Circulation 99:482-490

37. Gregorini L, Marco J, Palombo C, Kozakova M, Anguissola GB, Cassagneau B, Bernies M, Distante A, Marco I, Fajadet J, Zanchetti A (1998) Postischemic left ventricular dysfunction is abolished by alpha-adrenergic blocking agents. J Am Coll Cardiol 31:992-1001

38. Haude M, Caspari G, Baumgart D, Ehring T, Schulz R, Roth T, Koch L, Erbel R, Spiller P, Heusch G (2000) X-ray densitometry for the measurement of regional myocardial perfusion. Basic Res Cardiol 95:261-270

39. Heusch G, Baumgart D, Camici P, Chilian W, Gregorini L, Hess O, Indolfi C, Rimoldi O (2000) alpha-adrenergic coronary vasoconstriction and myocardial ischemia in humans. Circulation 101:689-694

40. Heusch G, Deussen A (1983) The effects of cardiac sympathetic nerve stimulation on perfusion of stenotic coronary arteries in the dog. Circ Res 53:8-15

41. Heusch G, Deussen A, Schipke J, Thamer V (1984) Alpha 1and alpha 2-adrenoceptor-mediated vasoconstriction of large and small canine coronary arteries in vivo. J Cardiovasc Pharmacol 6:961-968

42. Heusch G, Schulz R, Rahimtoola SH (2005) Myocardial hibernation: a delicate balance. Am J Physiol Heart Circ Physiol 288:H984-H999

43. Hoffman JI (1981) Why is myocardial ischaemia so commonly subendocardial? Clin Sci (Lond) 61:657-662

44. Hoffman JI, Spaan JA (1990) Pressure-flow relations in coronary circulation. Physiol Rev 70:331-390

45. Hsu LY, Kellman P, Arai AE (2008) Nonlinear myocardial signal intensity correction improves quantification of contrastenhanced first-pass MR perfusion in humans. J Magn Reson Imaging 27:793-801

46. Hundley WG, Lange RA, Clarke GD, Meshack BM, Payne J, Landau C, McColl R, Sayad DE, Willett DL, Willard JE, Hillis LD, Peshock RM (1996) Assessment of coronary arterial flow and flow reserve in humans with magnetic resonance imaging. Circulation 93:1502-1508

47. Iida H, Kanno I, Takahashi A, Miura S, Murakami M, Takahashi $\mathrm{K}$, Ono $\mathrm{Y}$, Shishido $\mathrm{F}$, Inugami A, Tomura $\mathrm{N}$ et al (1988) Measurement of absolute myocardial blood flow with $\mathrm{H}_{2}^{15} \mathrm{O}$ and dynamic positron-emission tomography. Strategy for quantification in relation to the partial-volume effect. Circulation 78:104-115

48. Iida H, Tamura Y, Kitamura K, Bloomfield PM, Eberl S, Ono Y (2000) Histochemical correlates of (15)O-water-perfusable tissue fraction in experimental canine studies of old myocardial infarction. J Nucl Med 41:1737-1745

49. Indolfi C, Piscione F, Rapacciuolo A, Esposito G, Esposito N, Ceravolo R, Di Lorenzo E, Maione A, Condorelli M, Chiariello M (1994) Coronary artery vasoconstriction after successful single angioplasty of the left anterior descending artery. Am Heart J 128:858-864

50. Jagathesan R, Barnes E, Rosen SD, Foale RA, Camici PG (2006) Comparison of myocardial blood flow and coronary flow reserve during dobutamine and adenosine stress: implications for pharmacologic stress testing in coronary artery disease. J Nucl Cardiol 13:324-332
51. Jerosch-Herold M, Seethamraju RT, Swingen CM, Wilke NM, Stillman AE (2004) Analysis of myocardial perfusion MRI. J Magn Reson Imaging 19:758-770

52. Jerosch-Herold M, Swingen C, Seethamraju RT (2002) Myocardial blood flow quantification with MRI by model-independent deconvolution. Med Phys 29:886-897

53. Julius BK, Vassalli G, Mandinov L, Hess OM (1999) Alphaadrenoceptor blockade prevents exercise-induced vasoconstriction of stenotic coronary arteries. J Am Coll Cardiol 33:14991505

54. Kaufmann PA, Camici PG (2005) Myocardial blood flow measurement by PET: technical aspects and clinical applications. J Nucl Med 46:75-88

55. Kaufmann PA, Gnecchi-Ruscone T, Yap JT, Rimoldi O, Camici PG (1999) Assessment of the reproducibility of baseline and hyperemic myocardial blood flow measurements with $15 \mathrm{O}$ labeled water and PET. J Nucl Med 40:1848-1856

56. Kern MJ, Lerman A, Bech JW, De Bruyne B, Eeckhout E, Fearon WF, Higano ST, Lim MJ, Meuwissen M, Piek JJ, Pijls NH, Siebes M, Spaan JA (2006) Physiological assessment of coronary artery disease in the cardiac catheterization laboratory: a scientific statement from the American Heart Association Committee on Diagnostic and Interventional Cardiac Catheterization, Council on Clinical Cardiology. Circulation 114:13211341

57. Kim RJ, Fieno DS, Parrish TB, Harris K, Chen EL, Simonetti O, Bundy J, Finn JP, Klocke FJ, Judd RM (1999) Relationship of MRI delayed contrast enhancement to irreversible injury, infarct age, and contractile function. Circulation 100:1992-2002

58. Kim RJ, Wu E, Rafael A, Chen EL, Parker MA, Simonetti O, Klocke FJ, Bonow RO, Judd RM (2000) The use of contrastenhanced magnetic resonance imaging to identify reversible myocardial dysfunction. N Engl J Med 343:1445-1453

59. Klocke FJ, Mates RE, Canty JM Jr, Ellis AK (1985) Coronary pressure-flow relationships. Controversial issues and probable implications. Circ Res 56:310-323

60. Knaapen P, Boellaard R, Gotte MJ, van der Weerdt AP, Visser CA, Lammertsma AA, Visser FC (2003) The perfusable tissue index: a marker of myocardial viability. J Nucl Cardiol 10:684691

61. Knaapen P, Germans T, Camici PG, Rimoldi OE, Ten Cate FJ, Ten Berg JM, Dijkmans PA, Boellaard R, van Dockum WG, Gotte MJ, Twisk JW, van Rossum AC, Lammertsma AA, Visser FC (2008) Determinants of coronary microvascular dysfunction in symptomatic hypertrophic cardiomyopathy. Am J Physiol Heart Circ Physiol 294:H986-H993

62. Knaapen P, Lubberink M (2008) Cardiac positron emission tomography: myocardial perfusion and metabolism in clinical practice. Clin Res Cardiol 97:791-796

63. Knaapen P, van Campen LM, de Cock CC, Gotte MJ, Visser CA, Lammertsma AA, Visser FC (2004) Effects of cardiac resynchronization therapy on myocardial perfusion reserve. Circulation 110:646-651

64. Kolyva C, Verhoeff BJ, Spaan JA, Piek JJ, Siebes M (2008) Increased diastolic time fraction as beneficial adjunct of alpha1adrenergic receptor blockade after percutaneous coronary intervention. Am J Physiol Heart Circ Physiol 295:H2054H2060

65. Kuhle WG, Porenta G, Huang SC, Buxton D, Gambhir SS, Hansen H, Phelps ME, Schelbert HR (1992) Quantification of regional myocardial blood flow using $13 \mathrm{~N}$-ammonia and reoriented dynamic positron emission tomographic imaging. Circulation 86:1004-1017

66. Kuo PH, Kanal E, Abu-Alfa AK, Cowper SE (2007) Gadolinium-based MR contrast agents and nephrogenic systemic fibrosis. Radiology 242:647-649 
67. Li X, Springer SC, Jerosch-Herold M (2008) First-pass DCEMRI with extravasating CR: Evidence for human myocardial capillary recruitment in adenosine-induced hyperemia. NMR Biomed 21

68. Lindner JR, Song J, Jayaweera AR, Sklenar J, Kaul S (2002) Microvascular rheology of Definity microbubbles after intraarterial and intravenous administration. J Am Soc Echocardiogr $15: 396-403$

69. Lorenzoni R, Rosen SD, Camici PG (1996) Effect of alpha 1adrenoceptor blockade on resting and hyperemic myocardial blood flow in normal humans. Am J Physiol 271:H1302-H1306

70. Marcus ML, Chilian WM, Kanatsuka H, Dellsperger KC, Eastham CL, Lamping KG (1990) Understanding the coronary circulation through studies at the microvascular level. Circulation $82: 1-7$

71. Marques KM, Knaapen P, Boellaard R, Lammertsma AA, Westerhof N, Visser FC (2007) Microvascular function in viable myocardium after chronic infarction does not influence fractional flow reserve measurements. J Nucl Med 48:19871992

72. Marques KM, Knaapen P, Boellaard R, Westerhof N, Lammertsma AA, Visser CA, Visser FC (2007) Hyperaemic microvascular resistance is not increased in viable myocardium after chronic myocardial infarction. Eur Heart J 28:2320-2325

73. Mathey DG, Chatterjee K, Tyberg JV, Lekven J, Brundage B, Parmley WW (1978) Coronary sinus reflux. A source of error in the measurement of thermodilution coronary sinus flow. Circulation 57:778-786

74. Meier P, Zierler KL (1954) On the theory of the indicatordilution method for measurement of blood flow and volume. J Appl Physiol 6:731-744

75. Meuwissen M, Siebes M, Chamuleau SA, van Eck-Smit BL, Koch KT, de Winter RJ, Tijssen JG, Spaan JA, Piek JJ (2002) Hyperemic stenosis resistance index for evaluation of functional coronary lesion severity. Circulation 106:441-446

76. Mosher P, Ross J Jr, McFate PA, Shaw RF (1964) Control of coronary blood flow by an autoregulatory mechanism. Circ Res $14: 250-259$

77. Nagamachi S, Czernin J, Kim AS, Sun KT, Bottcher M, Phelps ME, Schelbert HR (1996) Reproducibility of measurements of regional resting and hyperemic myocardial blood flow assessed with PET. J Nucl Med 37:1626-1631

78. Neglia D, Michelassi C, Trivieri MG, Sambuceti G, Giorgetti A, Pratali L, Gallopin M, Salvadori P, Sorace O, Carpeggiani C, Poddighe R, L'Abbate A, Parodi O (2002) Prognostic role of myocardial blood flow impairment in idiopathic left ventricular dysfunction. Circulation 105:186-193

79. Nitzsche EU, Choi Y, Czernin J, Hoh CK, Huang SC, Schelbert HR (1996) Noninvasive quantification of myocardial blood flow in humans. A direct comparison of the $[13 \mathrm{~N}] \mathrm{ammonia}$ and the [15O]water techniques. Circulation 93:2000-2006

80. Otani K, Masuda K, Asanuma T, Ishikura F, Beppu S (2006) Corrected quantification method to determine myocardial blood flow using real-time myocardial contrast echocardiography. J Am Soc Echocardiogr 19:973-981

81. Petersen SE, Jerosch-Herold M, Hudsmith LE, Robson MD, Francis JM, Doll HA, Selvanayagam JB, Neubauer S, Watkins $\mathrm{H}$ (2007) Evidence for microvascular dysfunction in hypertrophic cardiomyopathy: new insights from multiparametric magnetic resonance imaging. Circulation 115:2418-2425

82. Pijls NH, De Bruyne B, Smith L, Aarnoudse W, Barbato E, Bartunek J, Bech GJ, Van De Vosse F (2002) Coronary thermodilution to assess flow reserve: validation in humans. Circulation 105:2482-2486

83. Plein S, Kozerke S, Suerder D, Luescher TF, Greenwood JP, Boesiger P, Schwitter J (2008) High spatial resolution myocardial perfusion cardiac magnetic resonance for the detection of coronary artery disease. Eur Heart $\mathrm{J}$ [epub ahead of print]

84. Plein S, Schwitter J, Suerder D, Greenwood JP, Boesiger P, Kozerke S (2008) k-Space and time sensitivity encodingaccelerated myocardial perfusion MR imaging at $3.0 \mathrm{~T}$ : comparison with 1.5 T. Radiology 249:493-500

85. Rajappan K, Rimoldi OE, Dutka DP, Ariff B, Pennell DJ, Sheridan DJ, Camici PG (2002) Mechanisms of coronary microcirculatory dysfunction in patients with aortic stenosis and angiographically normal coronary arteries. Circulation 105:470 476

86. Rimoldi O, Schafers KP, Boellaard R, Turkheimer F, Stegger L, Law MP, Lammerstma AA, Camici PG (2006) Quantification of subendocardial and subepicardial blood flow using 15O-labeled water and PET: experimental validation. J Nucl Med 47:163172

87. Rosen BD, Lima JA, Nasir K, Edvardsen T, Folsom AR, Lai S, Bluemke DA, Jerosch-Herold M (2006) Lower myocardial perfusion reserve is associated with decreased regional left ventricular function in asymptomatic participants of the multiethnic study of atherosclerosis. Circulation 114:289-297

88. Rossen JD, Winniford MD (1993) Effect of increases in heart rate and arterial pressure on coronary flow reserve in humans. J Am Coll Cardiol 21:343-348

89. Sambuceti G, Marzilli M, Fedele S, Marini C, L'Abbate A (2001) Paradoxical increase in microvascular resistance during tachycardia downstream from a severe stenosis in patients with coronary artery disease: reversal by angioplasty. Circulation 103:2352-2360

90. Sambuceti G, Marzilli M, Mari A, Marini C, Schluter M, Testa R, Papini M, Marraccini P, Ciriello G, Marzullo P, L'Abbate A (2005) Coronary microcirculatory vasoconstriction is heterogeneously distributed in acutely ischemic myocardium. Am J Physiol Heart Circ Physiol 288:H2298-H2305

91. Schafers KP, Stegger L (2008) Combined imaging of molecular function and morphology with PET/CT and SPECT/CT: image fusion and motion correction. Basic Res Cardiol 103:191-199

92. Schafers M (2008) The future of molecular imaging in the clinic needs a clear strategy and a multidisciplinary effort. Basic Res Cardiol 103:200-202

93. Scharf SM, Bromberger-Barnea B, Permutt S (1971) Distribution of coronary venous flow. J Appl Physiol 30:657-662

94. Schelbert HR, Phelps ME, Huang SC, MacDonald NS, Hansen H, Selin C, Kuhl DE (1981) N-13 ammonia as an indicator of myocardial blood flow. Circulation 63:1259-1272

95. Schindler TH, Zhang XL, Vincenti G, Mhiri L, Lerch R, Schelbert HR (2007) Role of PET in the evaluation and understanding of coronary physiology. J Nucl Cardiol 14:589603

96. Schuurbiers JC, Slager CJ, Serruys PW (1994) Luminal volume reconstruction from angioscopic video images of casts from human coronary arteries. Am J Cardiol 74:764-768

97. Schwaiger M, Ziegler S, Nekolla SG (2005) PET/CT: challenge for nuclear cardiology. J Nucl Med 46:1664-1678

98. Siebes M, Verhoeff BJ, Meuwissen M, de Winter RJ, Spaan JA, Piek JJ (2004) Single-wire pressure and flow velocity measurement to quantify coronary stenosis hemodynamics and effects of percutaneous interventions. Circulation 109:756-762

99. Skyba DM, Jayaweera AR, Goodman NC, Ismail S, Camarano G, Kaul S (1994) Quantification of myocardial perfusion with myocardial contrast echocardiography during left atrial injection of contrast. Implications for venous injection. Circulation 90:1513-1521

100. Spaan JA (1985) Coronary diastolic pressure-flow relation and zero flow pressure explained on the basis of intramyocardial compliance. Circ Res 56:293-309 
101. Spaan JA, Piek JJ, Hoffman JI, Siebes M (2006) Physiological basis of clinically used coronary hemodynamic indices. Circulation 113:446-455

102. Struijker-Boudier HA, Rosei AE, Bruneval P, Camici PG, Christ F, Henrion D, Levy BI, Pries A, Vanoverschelde JL (2007) Evaluation of the microcirculation in hypertension and cardiovascular disease. Eur Heart J 28:2834-2840

103. Tong CY, Prato FS, Wisenberg G, Lee TY, Carroll E, Sandler D, Wills J (1993) Techniques for the measurement of the local myocardial extraction efficiency for inert diffusible contrast agents such as gadopentate dimeglumine. Magn Reson Med 30:332-336

104. Tong CY, Prato FS, Wisenberg G, Lee TY, Carroll E, Sandler D, Wills J, Drost D (1993) Measurement of the extraction efficiency and distribution volume for Gd-DTPA in normal and diseased canine myocardium. Magn Reson Med 30:337-346

105. Torres MA, Picano E, Parodi G, Sicari R, Veglia F, Giorgetti A, Marzullo P, Parodi O (1997) Flow-function relation in patients with chronic coronary artery disease and reduced regional function. A positron emission tomographic and two-dimensional echocardiographic study with coronary vasodilator stress. J Am Coll Cardiol 30:65-70

106. Toyota E, Koshida R, Hattan N, Chilian WM (2001) Regulation of the coronary vasomotor tone: what we know and where we need to go. J Nucl Cardiol 8:599-605

107. Uren NG, Crake T, Lefroy DC, de Silva R, Davies GJ, Maseri A (1994) Reduced coronary vasodilator function in infarcted and normal myocardium after myocardial infarction. N Engl J Med 331:222-227

108. Uren NG, Melin JA, De Bruyne B, Wijns W, Baudhuin T, Camici PG (1994) Relation between myocardial blood flow and the severity of coronary-artery stenosis. $N$ Engl J Med 330:1782-1788

109. van den Wijngaard JP, Kolyva C, Siebes M, Dankelman J, van Gemert MJ, Piek JJ, Spaan JA (2008) Model prediction of subendocardial perfusion of the coronary circulation in the presence of an epicardial coronary artery stenosis. Med Biol Eng Comput 46:421-432

110. van Rossum AC, Visser FC, Hofman MB, Galjee MA, Westerhof N, Valk J (1992) Global left ventricular perfusion: noninvasive measurement with cine MR imaging and phase velocity mapping of coronary venous outflow. Radiology 182:685-691
111. Vancraeynest D, Kefer J, Hanet C, Fillee C, Beauloye C, Pasquet A, Gerber BL, Philippe M, Vanoverschelde JL (2007) Release of cardiac bio-markers during high mechanical index contrast-enhanced echocardiography in humans. Eur Heart J 28:1236-1241

112. Verhoeff BJ, Siebes M, Meuwissen M, Atasever B, Voskuil M, de Winter RJ, Koch KT, Tijssen JG, Spaan JA, Piek JJ (2005) Influence of percutaneous coronary intervention on coronary microvascular resistance index. Circulation 111:76-82

113. Vogel R, Indermuhle A, Reinhardt J, Meier P, Siegrist PT, Namdar M, Kaufmann PA, Seiler C (2005) The quantification of absolute myocardial perfusion in humans by contrast echocardiography: algorithm and validation. J Am Coll Cardiol 45:754762

114. von Birgelen C, van der Lugt A, Nicosia A, Mintz GS, Gussenhoven EJ, de Vrey E, Mallus MT, Roelandt JR, Serruys PW, de Feyter PJ (1996) Computerized assessment of coronary lumen and atherosclerotic plaque dimensions in three-dimensional intravascular ultrasound correlated with histomorphometry. Am J Cardiol 78:1202-1209

115. Waters EA, Wickline SA (2008) Contrast agents for MRI. Basic Res Cardiol 103:114-121

116. Wei K, Jayaweera AR, Firoozan S, Linka A, Skyba DM, Kaul S (1998) Quantification of myocardial blood flow with ultrasoundinduced destruction of microbubbles administered as a constant venous infusion. Circulation 97:473-483

117. Weisse AB, Regan TJ (1974) A comparison of thermodilution coronary sinus blood flows and krypton myocardial blood flows in the intact dog. Cardiovasc Res 8:526-533

118. Westerhof N, Boer C, Lamberts RR, Sipkema P (2006) Crosstalk between cardiac muscle and coronary vasculature. Physiol Rev 86:1263-1308

119. Wijns W, Vatner SF, Camici PG (1998) Hibernating myocardium. N Engl J Med 339:173-181

120. Zeiher AM, Drexler H, Wollschlager H, Just H (1991) Endothelial dysfunction of the coronary microvasculature is associated with coronary blood flow regulation in patients with early atherosclerosis. Circulation 84:1984-1992

121. Zierler K (2000) Indicator dilution methods for measuring blood flow, volume, and other properties of biological systems: a brief history and memoir. Ann Biomed Eng 28:836-848 